\title{
Seven Zoster Reactivations in an Immune Competent Patient: How Many Is Too Many?
}

Rashid M. Rashid'1, MD, Kenneth D. Candido ${ }^{2}, \mathrm{MD}$ and Shariq Ibrahim², MD

From: ${ }^{1,2}$ Loyola University Medical Center, Maywood, IL: Dr. Rashid ${ }^{1}$ is in the MD PhD program, and Drs. Candido and Ibrahim $^{2}$ are with the Department of Anesthesiology Division of Pain Management

Address Correspondence: Rashid M. Rashid, MD 2160 South First Ave., Bldg 120 4th floor, Office of the Dean, Maywood, IL 60153.

E-mail: RashidRashid.MDPhD@yahoo.com Funding: None

Conflict of Interest: None. Manuscript received: $07 / 02 / 2006$

Revisions received: o9/06/2006

Accepted for publication: $10 / 23 / 2006$
Herpes zoster virus (HZV) reactivation is commonly reported in elderly or immune compromised patients. However, certain presentations are rarely reported in immune competent patients. Here we report a rare case of recalcitrant HZV infection, including 7 reactivations over 3 years, in an immune competent patient. Due to the pain experienced, this patient self-referred to our clinic, and thus bypassed other specialties. As pain management specialists, it is critical to be aware of such presentations, the clinical implications involved, and management options to consider.

Key words: Zoster, herpes zoster, zoster reactivation, shingles, post-herpetic neuralgia, Protein $\mathbf{S}$ deficiency, epidural analgesia

Pain Physician 2007; 10:301-304
D ain from herpes zoster virus (HZV) reactivation and post herpetic neuralgia (PHN) is an everincreasing part of the pain clinic patient population. However, such presentations in younger patients are normally associated with an immune compromised state. Although rare reports exist of zoster in immune competent patients $(1,2)$, this is the first report of as many as 7 reactivations in less than 36 months. In this report, we further review a possible link of HZV with protein S deficiency, as a potential harbinger of more grave pathology. We also discuss our central theme of a unique approach to pain control in such patients.

\section{Case Report}

A 38-year-old female with zoster-related pain (ZRP) was referred to our pain management clinic. The patient had a total of $7 \mathrm{HZV}$ reactivations in the past 3 years. Each reactivation was at different dermatomal levels, on different sides of the body, and associated with remnant pain for several months afterwards (Fig. 1). At no time did the patient develop 


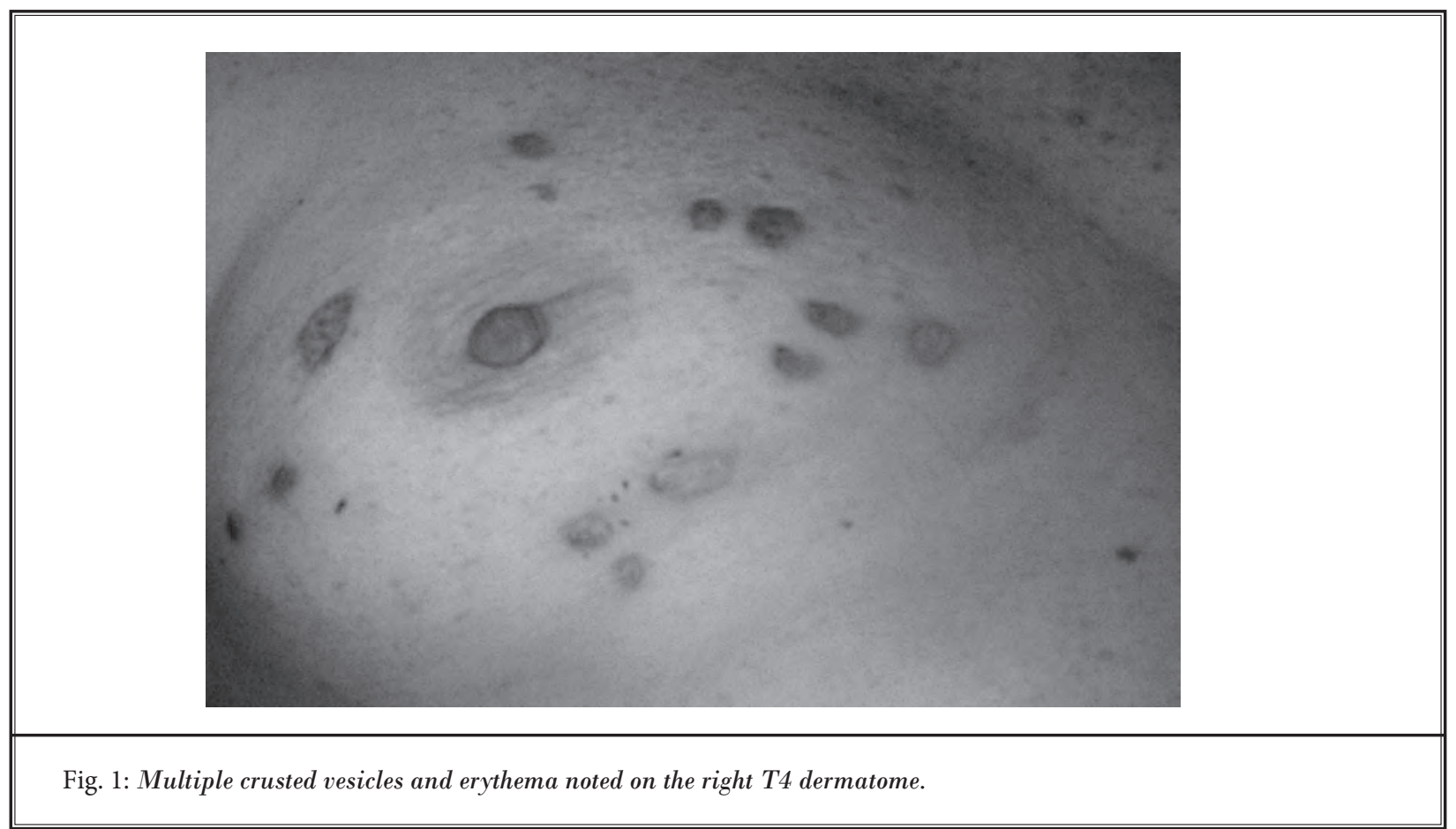

lesions in more than 2 contiguous dermatomes, or lesions otherwise not confined to the thorax. The clinical presentation included vesicles and crusted erosions associated with tactile allodynia. No other associated illnesses or specific stress triggers existed with the reactivations, though the patient reported many "life stresses" with emotional upheaval. The patient has a complicated past medical history, but was tested for Herpes Simplex virus (HSV) and Human Immunodeficiency virus (HIV) and found to be seronegative. Notable history included multiple thromboembolic events since age 18 , a diagnosis of protein $S$ deficiency determined 1 year ago, arachnoiditis following lumbar discectomy surgery, asthma, and a neurogenic bladder. The patient and family refused further testing to better assess the inherited versus acquired origin of the protein $\mathrm{S}$ deficiency. An outside hospital placed a permanent implanted spinal cord stimulator as an analgesic modulation technique for the arachnoiditis. Outside of sporadic hospitalizations, the patient lives an independent productive life.

In the Pain Management Center, the patient was encouraged to return during actual outbreaks. Treatment was with oral antiviral agents, Lidoderm $\circledast 5 \%$ patch, tramadol tablets, amitriptyline, hydrocodone and acetaminophen, and epidural injections. Over the course of her visits to control ZRP, she underwent 6 fluoroscopically-guided thoracic epidural injections (TESI) of methylprednisolone acetate (Depomedrol $\circledast$ ), $120 \mathrm{mg}$, in $4 \mathrm{~mL}$ of $1 \%$ preservative-free lidocaine hydrochloride (total volume $=6 \mathrm{~mL}$ placed at the dermatomal level of the outbreak). On her first 2 visits, the treatment was for PHN since the pain had persisted for more than 1 month after healing of the rash. She then returned for treatment during actual outbreaks, at our prompting. Following each TESI, the patient noted a regression and disappearance of the lesions with a reduction in her pain level so that she was able to discontinue her use of hydrocodone. Typically, lesions regressed within a week's time following the TESI blocks, and did not recur for up to 2 months. Each reactivation resolved without complications, scarring, or long-term sequelae. She was referred to immunology for an immune deficiency work up. No positive findings were noted via immunology studies including serology of $\lg G, A$, and $M$.

\section{Discussion}

The number of immunocompromised patients from HIV disease and malignancy is increasing (3). As such, HZV reactivation, ZRP, and PHN pain control have become more important and the subject of multiple reviews (4-6). However, it is atypical to see reac- 
tivations in younger patients with no history of malignancy and no immune deficits. A literature search found no other case of 7 reactivations in an immune competent patient.

The rarity of these cases excludes large-scale studies. The cause for such reactivations has been speculated upon, though not proven (2). For example, a recent report in immune competent children suggested the possibility of an immature immune response (7). However, in our case, we noted the history of protein S deficiency. Protein $S$ deficiency has been associated with HZV (8). In children, only varicella has been reported to cause protein $\mathrm{S}$ deficiency (8). This is believed to be a transient event occurring shortly after clinical varicella presentation, lasting up to 6 months $(9,10)$. The trigger is believed to be an antibody generated during infection that targets the $\mathrm{N}$-terminal part of protein $\mathrm{S}$ (11). Though zoster represents localized reactivation of varicella, it does cause complications such as encephalitis and hemiparesis, and it is relevant to consider the consequences of further exacerbating protein S deficiency, especially for an adult (12). Other causes of acquired protein S deficiency, including HIV and Behcet's disease, were absent in our patient $(13,14)$.

Inherited protein $S$ deficiency is predominantly autosomal dominant. The degree of symptomatology varies in relation to the level of the deficiency (14). In inherited cases, familial protein S deficiency can present as thrombosis in the most susceptible family member during varicella infection, while not affecting other family members (15). In this patient, the initial thrombotic episode was believed to be due to use of contraceptives, cigarette smoking, and an immobilizing knee brace. Since no other family member developed thromboses, it may be that she is the most susceptible member with familial protein $\mathrm{S}$ deficiency. Unfortunately, due to the expensive and burdensome testing required of the patient and family, we could not define the inherited or acquired nature of her protein S deficiency.

Another possibility to be identified is the relationship of recurrent zoster as an initial presenting sign or harbinger of malignancy or immunocompromisation (16). This case emphasizes the importance of a complete medical workup. As in previous reports with no other findings beyond HZV recurrence, we remain optimistic on the ultimate outcome (2). Nevertheless, the patient was referred to Immunology and is being monitored for potential changes in immune status or malignancy.
When managing such patients, pain treatment is an essential part of appropriate care. However, the use of epidural steroid injections to treat zoster-related pain is controversial. In 2 separate prospective, randomized, controlled trials, intrathecal methylprednisolone 60 $\mathrm{mg}$ mixed with lidocaine ( $3 \mathrm{~mL}$ of $3 \%$ solution) proved superior to epidural steroid injections or subarachnoid lidocaine only in treating patients with long-standing, refractory PHN $(17,18)$. Nevertheless, some have implicated the epidural use of another corticosteroid, trimacinolone, in $40 \mathrm{mg}$ or $\mathbf{8 0} \mathrm{mg}$ doses, during active HZV eruptions (19). However, in 3 cases presented in the study by Sen and Yarmush, there was no indication that diagnostic examinations corroborated the clinical impression that patients had developed acute zoster, thus no conclusions could be drawn regarding implied associations (19). In our patient, who did manifest clinical features of recurrent $\mathrm{HZV}$ reactivations and who had proved seronegative for other viral exanthema, the use of epidural methylprednisolone mixed with lidocaine produced a rapid and complete resolution of both the rash and the associated ZRP. No reactivation of the lesions or symptoms could be causally or temporally related to these interventions.

It is possible that the analgesia experienced by our patient resulted from the sympathetic block that accompanies the administration of local anesthetic into the epidural space. As early as 1938 , sympathetic blocks proved effective in treating symptoms of ZRP (20). Tenicela et al validated the concept of sympathetic blocks in relieving the pain of zoster outbreaks in a randomized, double-blind, placebo controlled, cross-over study, with $90 \%$ of bupivacaine treated patients responding favorably, vs. $20 \%$ of saline controls (21). Lundborg offered corroborating evidence for a "fiber dissociation" mechanism amenable to sympathetic blocks in 1975 (22). He demonstrated that small fibers $(A-\delta, C)$ could survive prolonged ischemia and hypoglycemia (commonly considered to be a mechanism of pain associated with the intense inflammatory reaction caused by $\mathrm{HZV}$ reactivation) and subsequently recover, in contradistinction to larger fibers (22). Sympathetic blocks administered early after the onset of the zoster outbreak, then, would likely reduce the ischemic and hypoglycemic insult, allowing the smaller sensory fibers to recover function, and also would reduce the resultant allodynia $(23,24)$. As the mechanism of pain related to $\mathrm{HZV}$ remains elusive, and $\mathrm{PHN}$ remains a serious complication of $\mathrm{HZV}$ activation in inadequately treated patients, we remain commit- 
ted to offering this treatment to selected individuals for whom epidural corticosteroids are not otherwise contraindicated. This seems intuitive based on the possible relationship of PHN with ongoing peripheral nociceptive excitation combined with a central deafferentation mechanism, both suggested as interactive in the etiology of PHN (25).

In conclusion, this case highlights several themes. Firstly, not all cases of zoster are the same, and while we provide symptomatic relief, we need to work up possible causes of immune deficits. Considering the rarity of reports of zoster in immune competent patients, we recommend performing a full workup and consulting other subspecialties after 2 episodes of recurrent zoster in immune competent patients, to minimize the severity of complications that may arise (7). Also notable is the possible beneficial result that may be achieved from early and aggressive analgesic management of zoster outbreaks. On the most recent 4-month follow up visit, our patient's latest outbreak had resolved and no PHN was present. We are optimistic that the increasing interval between eruptions may imply a "burning-out" of whatever mechanism is inciting the zoster reactivations. Treating patients early, while the outbreak is active, can prevent PHN (24). Efforts to control pain, even in the face of repetitive "recalcitrant" responses to the initial attempts, continues to be important.

\section{References}

1. Gupta LK, Kuldeep CM, Mittal A, Singhal $\mathrm{H}$ : Multidermatomal herpes zoster in an immunocompetent female. Indian J Dermatol Venereol Leprol 2005; 71: 210211.

2. Raza N, Iqbal P, Anwer J: Recurrence of herpes zoster in an immunocompetent adult male. J Ayub Med Coll Abbottabad 2005; 17: 80-81.

3. MMWR Sexually transmitted diseases treatment guidelines 2002. Centers for Disease Control and Prevention. MMWR Recomm Rep 2002; 51: 1-78.

4. Haanpaa M, Laippala P, Nurmikko T. Pain and somatosensory dysfunction in acute herpes zoster. Clin J Pain 1999; 15: 78-84.

5. Baron R. Post-herpetic neuralgia case study: optimizing pain control. Eur J Neurol 2004; 11 Suppl 1:3-11.

6. Argoff CE, Katz N, Backonja M. Treatment of postherpetic neuralgia: a review of therapeutic options. J Pain Symptom Manage 2004; 28: 396-411.

7. Takayama N, Yamada H, Kaku H, Minamitani M. Herpes zoster in immunocompetent and immunocompromised Japanese children. Pediatr Int 2000; 42: 275-279.

8. Pashankar D, Robinson A, Tait RC. Protein S deficiency after varicella. J Pediatr 1996; 129: 315-316.

9. Nguyen P, Reynaud J, Pouzol P, Munzer M, Richard O, Francois P: Varicella and thrombotic complications associated with transient protein $C$ and protein $S$ deficiencies in children. Eur J Pediatr 1994; 153: 646-649.
11. Regnault V, Boehlen F, Ozsahin H, Wahl $D$, de Groot PG, Lecompte T, de Moerloose $\mathrm{P}$. Anti-protein $\mathrm{S}$ antibodies following a varicella infection: detection, characterization and influence on thrombin generation. J Thromb Haemost 2005; 3: 1243-1249.

10. Peyvandi F, Faioni E, Alessandro Moroni G, Rosti A, Leo L, Moia M. Autoimmune protein $S$ deficiency and deep vein thrombosis after chickenpox. Thromb Haemost 1996; 75: 212-213.

12. Gnann JW Jr. Varicella-zoster virus: atypical presentations and unusual complications. J Infect Dis 2002; 186 Suppl 1: S91-98.

13 Erbe $M$, Rickerts V, Bauersachs RM, Lindhoff-Last E. Acquired protein $\mathrm{C}$ and protein $\mathrm{S}$ deficiency in HIV-infected patients. Clin Appl Thromb Hemost 2003; 9: 325-331.

14. Guermazi S, Hamza M, Dellagi K. Protein S deficiency and antibodies to protein $S$ in patients with Behcet's disease. Thromb Res 1997 1; 86: 197-204.

15. Comp PC, Nixon RR, Cooper MR, Esmon CT. Familial protein S deficiency is associated with recurrent thrombosis. J Clin Invest 1984; 74: 2082-2088.

16. Cappelli R, Masotti L, Zanelli G, Battis tini S, Forconi S. Deep vein thrombosis during varicella in a child with factor $\mathrm{V}$ Leiden mutation and familial deficiency of protein S. Thromb Haemost 2001 Feb; 85:370.

17. Kikuchi A, Kotani N, Sato T, Takamura K, Sakai I, Matsuki A. Comparative therapeutic evaluation of intrathecal versus epidural methylprednisolone for longterm analgesia in patients with intractable postherpetic neuralgia. RAPM 1999; 24: 287-293.

18. Kotani N, Kushikata T, Hashimoto $H$, Kimura F, Muraoka M, Yodono M, Asa M, Matsuki A. Intrathecal methylprednisolone for intractable postherpetic neuralgia. NEJM 2000; 343:1514-1519.

19. Sen S, Yarmush J. Poster Presentation: ASRA Annual Pain Meeting; 2005, Miami FL.

20. Rosenak S. Procaine injection treatment of herpes zoster. Lancet 1938; 1056-1058.

21. Tenicela R, Lovasik D, Eaglstein: Treatment of herpes zoster with sympathetic blocks. Clin J Pain 1985; 1:63-67.

22. Lundborg G. Structure and function of the intraneural microvessels as related to trauma, edema formation, and nerve function. J Bone Joint Surg 1975; 57, 938-948.

23. Colding A. Treatment of pain: organization of a pain clinic: treatment of acute herpes zoster. Proc R Soc Med 1973; 66: 541-543.

24. Winnie A, Hartwell P. Relationship between time of treatment of acute herpes zoster with sympathetic blockade and prevention of post-herpetic neuralgia: clinical support for a new theory of the mechanism by which sympathetic blockade provides therapeutic benefit. Reg Anes 1993; 18:277-282.

25. Sakai T, Tomiyasu S, Yamada H, Sumikawa K. Evaluation of allodynia and pain associated with postherpetic neuralgia using current perception threshold testing. Clin J Pain 2006; 22:359-362. 